\title{
Dentro do círculo: sobre teatro e literatura dramática
}

\author{
José Maria Vieira Mendes
}

\begin{abstract}
A major trend in theatre studies divides theatre into two types: the literary and the non-literary theatre. This essay demonstrates how such partition restricts the way we look at performances and read drama, but also how it influences the relationship between both arts, confining them to a narrative of tensions within an antithetic and dual scheme. For that reason, when we say that theatre is different from literature, this assertion is necessarily accompanied by the presumably antithetic claim that theatre and literature are identical, as if one assertion could not be understood without the other. This essay seeks an alternative to the preponderance of these ideas in order to escape from their authority. By following a certain tradition of epistemology, one can find an ampler perspective, one that liberates theatre and literature from a correlationist logic sustained by a concept of knowledge that aims to achieve certainty and unanimity. Through the use of a different idea of knowledge and being, we will be better positioned to meet and acknowledge the invisibility of things (be it a performance, a play or a person).
\end{abstract}

THEATRE / DRAMA / THEATRE STUDIES / CORRELATIONISM / ONTOLOGY

INTRODUÇÃO

Nas mais recentes décadas, tem-se assistido, no campo da filosofia, a uma crítica do que é identificado como «correlacionismo kantiano». ${ }^{1} \mathrm{O}$ dilema com que essa crítica se confronta, e que nos apresenta como tratando-se de uma herança do nascimento da filosofia moderna (Descartes e Kant), pode ser resumido do seguinte modo: não é possível acedermos às coisas em si, apenas temos acesso a efeitos ou fenómenos que resultam da nossa relação com essas coisas - e no entanto, as coisas em si existem.

1 Por exemplo, Meillassoux (2006), e um conjunto de autores associados ao «realismo especulativo», «novo realismo», à «object-oriented ontology» ou ao «pós-humanismo». 
Para caracterizar este dilema, recorre-se com frequência à expressão «círculo hermenêutico» utilizada nos estudos literários para se referir à circunstância de que a compreensão de um texto enquanto todo se estabelece através de cada uma das partes e do entendimento que cada indivíduo tem de cada uma dessas partes na sua relação com o todo. Por isso, nem o texto no seu conjunto nem cada uma das partes podem ser entendidos sem ter em conta a relação entre eles. Na história da filosofia mais recente, Heidegger é um dos exemplos recuperados por estas correntes de pensamento para encontrar um modo de lidar com o círculo (Harman, 2002, 2007). Em A Origem da Obra de Arte, o filósofo alemão aborda a pergunta «o que é uma obra de arte?» com o facto de a resposta depender da relação da obra de arte com o conceito «arte», que por sua vez não pode ser entendido sem ter em conta a obra. Nas palavras do próprio:

O que a arte seja, tem de apreender-se a partir da obra. O que seja a obra, só o podemos experienciar a partir da essência da arte. Qualquer um nota com facilidade que nos movemos em círculo. O senso comum exige que se evite o círculo, porque constitui uma violação da lógica. (Heidegger, 2008: 12)

Esta «violação da lógica» é o terreno onde certa crítica ao correlacionismo kantiano se coloca e onde este ensaio procura situar a já velha questão da relação entre teatro e literatura e entre literatura dramática e teatro. Como procurarei demonstrar, tanto a crítica teatral como as instituições, espectadores, leitores e grande parte do discurso que junta na mesma frase as palavras «teatro» e «literatura» encerram-se num círculo hermenêutico que fazem por desconsiderar na tentativa de escapar à violação da lógica. À custa desta posição, que considero ser paralisadora de olhares e pensamento, capturam e caricaturam espetáculos e textos, limitam-lhes significados, resguardando assim o sujeito epistemológico do confronto consigo próprio na relação com entidades flutuantes, espectrais e que habitam simultaneamente múltiplos campos de significado. O objetivo será então o de não apenas tornar visíveis as limitações como fornecer instrumentos e pensamento para lidar com esta tradição correlacionista, de modo que estejamos mais disponíveis para reconhecer identidades complexas no campo do teatro e da literatura dramática. 
No ensaio «Teatro e literatura» (1989), Osório Mateus, a quem pode ser justamente atribuída a paternidade dos estudos teatrais portugueses, marca os parágrafos com esta frase que se repete como um refrão: «Teatro e literatura são artes diferentes.» $\mathrm{O}$ contexto da asserção é o de um tempo em que, em Portugal, os estudos de teatro se fazem pelo lado da filologia, e em que nem sempre se distingue literatura dramática de teatro. Poderia resumir-se o argumento de Mateus como tratando-se da defesa da necessidade de se separar ambas as artes (teatro e literatura) de modo a aproximá-las (encontrar «zonas de coincidência» [Mateus, 2002: 217]). Exposto assim, surge a evidência, não notada pelo autor, de uma contradição: para quê separar se o objetivo é aproximar?

Creio que o paradoxo não é reconhecido por Osório Mateus porque o entendimento que tem de separação de identidades ou de diferença entre coisas se insere numa lógica de relação ou correlação que perpetua natural e obedientemente uma ideia de teatro dominante. Esta ideia de teatro apenas contempla a diferença entre teatro e literatura se ela for pensada na sua relação antinómica com a afirmação de que teatro e literatura são artes idênticas. A separação entre ambas as artes, apesar de declarada, não chega a acontecer, porque a identidade de cada uma delas, tal como o sentido da afirmação de Osório Mateus, apenas existe em confronto com o seu oposto.

Este contexto é significativo e condiciona a asserção porque a enquadra numa contenda com décadas de história. Quando Max Herrmann abre, em Berlim, na Alemanha, a primeira cátedra universitária de Estudos de Teatro, no início do século $\mathrm{XX}^{2}$, fá-lo seguindo o princípio de que a história do teatro se deve concentrar não no texto dramático, como até então se fazia, mas no espaço. ${ }^{3}$ Este nascimento de uma identidade conquista-se por demarcação negativa. A diferenciação é tratada como uma ação emancipatória e reativa, seguindo aliás a retórica de figuras da história do teatro como Gordon Craig ou Antonin Artaud, gesto este que, décadas mais tarde, continuará a marcar o discurso sobre teatro e literatura, como se nota, já no final do século, em Hans-Thies Lehmann,

2 Aponta-se como data simbolicamente inicial um curso de história do teatro alemão lecionado pelo professor e germanista Max Herrmann, em 1900, na Universidade Friedrich-Wilhelm, em Berlim, atualmente Universidade Humboldt, embora só em 1923, depois de ultrapassados entraves financeiros e políticos, fosse inaugurado o Instituto para os Estudos de Teatro na Universidade de Berlim. Cf. Corssen (1998) e Klier (1981). 
quando escreve no icónico Teatro Pós-Dramático: «O teatro e o drama existiram e continuam a existir numa relação de contradições tensas. Enfatizar este facto e considerar toda a extensão das suas implicações é o primeiro pré-requisito para uma compreensão adequada do novo e mais recente teatro» (Lehmann, 2005: 73).

A tensão histórica entre teatro e literatura no campo do teatro tem alimentado duas grandes tendências que formam dois campos: o teatro literário ou de texto e o teatro antiliterário ou pós-dramático. $\mathrm{O}$ espetáculo-caricatura da primeira tendência não se faz sem um texto de literatura dramática e toma todas as decisões a partir da interpretação das informações que esse texto fornece: número de atores, cenário, texto a ser dito em palco, figurinos, etc. O espetáculo da segunda tendência é habitualmente caracterizado como o espetáculo que não parte de um texto literário. Nesta arrumação, o teatro literário será supostamente um teatro que está mais próximo da literatura, dos que gostam de literatura, e o teatro não-literário mais próximo do teatro, da performance, do espaço.

Esta divisão dual assenta no reconhecimento de que há duas artes envolvidas na história do teatro (a literatura e o teatro) que, supostamente desde que teatro é teatro, procuram um modo de coabitação. A diferença entre uma e outra é aliás descrita recorrendo-se a um conjunto de clichés que as apreendem e que marcam as possibilidades de relação entre elas. Se o teatro é a arte do corpo, a literatura é a arte das letras; se o teatro é uma arte tridimensional, a literatura é uma arte bidimensional; se o teatro é uma arte efémera, a literatura garante a eternidade; se o teatro se vê, a literatura lê-se; se o teatro é coletivo, a literatura é solitária; se o teatro é uma arte de paixões e sentimento, a literatura traz consigo a razão e o pensamento...

Cada uma destas duas disciplinas relaciona-se em dependência antinómica com a disciplina outra. Isto implica olhar para o teatro como o contrário ou oposto da literatura, e vice-versa. É por isso que é difícil declarar a diferença entre teatro e literatura sem que essa afirmação seja lida como uma tomada de posição relativamente a uma contenda entre literários e antiliterários. É por isso também que espetáculos que não sigam um texto dramático são muitas vezes lidos e classificados como irresponsáveis, da moda, atualizados ou contemporâneos, e os espetáculos literários como sábios, clássicos, antiquados ou conservadores, consoante a posição na barricada escolhida pelo observador. Quando se entra aliás no campo das contendas, a relação entre teatro e literatura pode desenhar-se com a ajuda da figura quiasmática, em que cada um 
dos duais em causa carrega consigo uma classificação moralista: se para uns o teatro literário é bom e o antiliterário mau, para outros o literário é mau e o antiliterário bom. É nesta discussão que Osório Mateus insere o seu «teatro e literatura são artes diferentes» e é esse ainda hoje o seu sentido predominante, mesmo quando, proferindo esta mesma asserção, se pretenda postular uma evidente e mera diferença entre duas coisas (teatro é diferente de literatura como uma cadeira é diferente de plutónio, do sistema solar ou de um almoço).

Apesar da aparente simetria, a norma, que, de acordo com as histórias de teatro, nasce por volta de finais do século XVII, com o início do teatro burguês e de autores como Molière ou Goldoni, é ainda a literária. É para este tipo de teatro que está preparada a maioria das instituições teatrais ocidentais, os seus financiamentos ou os concursos e prémios de literatura dramática. Em paralelo foi-se assistindo ao surgimento de uma «alternativa» teatral que conquistou espaço institucional na segunda metade do século xx e que é lida numa relação de oposição, ganhando hoje uma visibilidade quase equiparável ao modelo anterior (Lehmann, 2005: 3). A relação antinómica não é pois totalmente simétrica, porque se identifica nela um dos membros do par como mais «normal» do que o outro. Trata-se de uma relação do mesmo tipo da que rege os pares heterossexualidade e homossexualidade, branco e negro, homem e mulher ou maioria e minoria, em que um dos duais serve de medida da normalidade ou representa a tradição identitária, e o outro a exceção, a anormalidade, mas também o rompimento ou a inovação.

Esta esquematização é por alguns considerada artificial, antiquada ou não operativa, no entanto é inegável que se trata de uma mitologia com uma influência abrangente. ${ }^{4}$ De um modo mais ou menos ínvio, ela valida discursos, sustenta lugares-comuns e estudos científicos, organiza o campo teatral (artistas, teatros e festivais) e perpetua verdades naturalizadas e olhares viciados. Teatro e literatura dramática estão invariavelmente sujeitos a este contexto que condiciona asserções, palavras e objetos.

Encontro nesta correlação entre duas artes no contexto teatral um círculo hermenêutico, na medida em que cada uma das partes não pode ser entendida sem que se tenha em conta a relação entre elas. Não há teatro sem a sua relação com a literatura, tal como não há literatura dramática sem a sua relação com o teatro. Nenhum dos elementos existe

4 Não haverá espaço neste ensaio para apresentar alguns dos muito exemplos, mas para os mais céticos sugiro Uma Coisa não É Outra Coisa (Vieira Mendes, 2016), onde documento este diagnóstico com inúmeros exemplos. 
sem a presença do seu par. Este vício circular perpetua uma ideia normativa de teatro que serve os objetos literários ou teatrais (e os observadores de ambas) que nela se queiram encaixar e condena à invisibilidade textos e espetáculos (e os observadores de ambos) que se queiram relacionar com outras disciplinas, artes, objetos, acontecimentos ou identidades. Ou seja, a imersão num círculo correlacionista limitado a uma lógica antinómica (teatro contra literatura, teatro literário contra teatro não-literário) não só limita o espectro identitário de textos e espetáculos, por via de preconceitos e vontades do observador que procura no que vê o que sabe que existe, como também potencia ansiedades e insatisfações nos seus observadores e praticantes ao retirar-lhes a capacidade de lidar com a não-presencialidade das coisas. A teoria converte as coisas em objetos (Heidegger), reduzindo-as a caricaturas e despindo-as de uma possibilidade infinita de relações.

Para ilustrar esta cegueira epistemológica (e negação ontológica) e as suas consequências, debruçar-me-ei em seguida sobre os seus efeitos na literatura dramática e no modo como este círculo correlacionista afeta os textos que são enquadrados dentro do género dramático. A separação com o objetivo de uma aproximação, que se lê no ensaio de Osório Mateus, tem vindo a contribuir para uma dependência da literatura dramática do teatro, colocando-a numa condição em tudo semelhante ao modelo contra o qual argumenta o pensamento que Osório Mateus ilustra. Se o interesse da asserção de Mateus é o de reconhecer que tanto o teatro como a literatura dramática precisam de áreas de estudo diferenciadas de modo que se abram possibilidades de relação no olhar sobre espetáculos e textos dramáticos, ao promover uma aproximação entre literatura dramática e teatro o autor recua e regressa a um constrangimento que fecha e diminui - é um melhor leitor de literatura dramática quem tem relações privilegiadas com o teatro ou quem conhece melhor o teatro. Como resultado desta posição, assiste-se a uma captura da literatura dramática pelo teatro que faz com que a sua existência dependa de uma certa ideia de teatro, das instituições teatrais e do espectador. 
Será difícil encontrar hoje quem identifique a literatura dramática como textos escritos em diálogos ou compostos por dois textos, o primário (os diálogos) e o secundário (as rubricas) ${ }^{5}$, depois de diferentes dramaturgos terem quebrado todos os formalismos tradicionais. A variedade, que passou por rompimentos vários (simbolistas, surrealistas, dadaístas, futuristas, o absurdo, o épico, o didático, o lírico, etc.), testa as tentativas de encaixar a literatura dramática num conjunto de regras tipográficas, temáticas ou formais (cf. Szondi, 1996), como vem a suceder, em idênticos períodos, com os restantes géneros literários.

À falta de referência formal, passou a caracterizar-se a especificidade do texto dramático com a ajuda de atributos mais abstratos ou abrangentes sustentados por uma certa ideia de teatro. Refiro-me à pressuposição de um teatro por ver, um espetáculo latente («peça a ser feita» é a expressão pirandelliana (apud Sarrazac [2012: 11]) ou uma oralidade própria, que permitirá adequar o texto à boca de atores ou ainda um odor a ação, a drama. Tal definição de literatura dramática arrasta consigo o princípio de que o dramaturgo será mais competente se for um «técnico bem próximo» do espetáculo e da sua produção, devendo ser chamado para o «trabalho específico de cena» (Mateus, 2002: 217), assim como valida o argumento de que determinado texto falha porque não é teatral ou que a sua transposição para o palco não resulta porque não tem nele teatro que o permita.

Este tipo de caracterização topológica vale-se de uma convivência próxima e histórica da literatura dramática com o teatro que define a sua identidade, mas também depende de um certo olhar sobre o teatro, da pressuposição de uma ideia imutável de teatro que, graças à constância, pode ser encontrada no texto dramático. Só se o dramaturgo e o seu leitor souberem o que é teatro, só quem tiver resposta para a pergunta «o que é teatro?» poderá exigir de um texto de literatura dramática que este contenha teatro.

Este modo apressado de reconhecer teatro e de atribuir identidade ao texto dramático (que só o é porque tem nele teatro) atropela a lógica. Ao autorizar uma hierarquização de significados na interpretação de um texto dramático, constrange o leitor sem uma justificação consistente que a torne necessária. Mesmo aceitando que existe «o teatro», por que 
motivo temos de o encontrar na literatura dramática? Esta pergunta não só não é respondida como nunca é formulada. E quando a resposta é «para que se distinga a literatura dramática dos outros géneros literários», não é suficiente, não estamos a responder à pergunta, porque terem açúcar, alma, paixão ou uma bacia cor-de-rosa poderia igualmente distinguir a literatura dramática de outros géneros. Mais, há quem encontre o tal «teatro» em romances, cinema, episódios quotidianos, e isso não faz de tais acontecimentos ou coisas literatura dramática.

Como consequência da procura de teatro em textos dramáticos, todos os objetos (textos dramáticos) que não joguem os seus sentidos na relação com esta ideia consensual de teatro tornam-se invisíveis ou então são empurrados e torcidos de modo a corresponderem a ela. E assim o leitor de teatro sente-se na obrigação de imaginar um palco e uma encenação, cenários e figurinos, luzes, atores, de encontrar «teatro», muitas vezes na sua versão mais inócua e ingénua, no texto que lê.

Mas o que mais debilita esta retórica é o teatro que se procura no texto dramático variar de acordo com o enunciador da frase, uma violação da lógica que não é reconhecida. Quando se lê o texto de literatura dramática na sua relação com o teatro, lê-se o texto em função de certo teatro, em função do que o leitor considera ser o teatro. No entanto, o que uma expressão como a «teatralidade» do texto dramático pressupõe é que o teatro ou o teatral é uma essência inamovível, fixa, referencial e independente das obras e de quem as lê. $\mathrm{O}$ teatro do autor dramático tem de ser o mesmo do leitor ou intérprete ou então o leitor ou intérprete procura o teatro do autor, o que ficou perdido no tempo e geografia, apoiando-se, nessa busca, numa ideia de história independente do historiador. Só aceitando o teatro como identidade autónoma de circunstâncias e de espetáculos podemos utilizá-lo como característica diferenciadora e válida para a crítica e a interpretação. Aliás, é porque existe um preconceito teatral (cf. Barish, 1985) que entendemos quem afirma ter encontrado uma característica teatral em determinado texto.

É comum dizer-se que um texto dramático «não convencional» como Descrição de Um Quadro (1985), de Heiner Müller, é um texto que procura fugir ao teatro, que se afirma contra o teatro. Do mesmo modo, considera-se por oposição um texto «mais convencional», como Morte de Um Caixeiro Viajante, um texto com teatro dentro. A diferenciação entre estes dois textos, sobretudo quando comparados, faz-se a custas de uma suposta relação que ambos sugerem com o teatro, como se o teatro fosse apenas um para os dois textos. A «rebeldia» de Müller é olhada como 
um desafio, um obstáculo ou resistência ao teatro. Ora, o teatro de que se fala não é uma identidade fixa, eterna e sempre igual. O teatro no tempo de Ésquilo não é o teatro de Shakespeare, tal como o teatro anglo-americano não é o mesmo que o teatro alemão, o teatro de Heiner Müller não é o mesmo que o de Henry Miller, o teatro de Descrição de Um Quadro não é o mesmo de Quarteto, outra peça de Heiner Müller, o teatro de Ésquilo para alguém do início do século xıX não é o mesmo que o teatro de Ésquilo para alguém no início do século XXI, etc.

Seguindo o raciocínio de Heidegger, não há teatro sem obras nem obras sem teatro, pelo que a ideia de que a literatura dramática tem teatro em si não pode passar por cima de um confronto com uma violação da lógica que deve fazer repensar e abalar a estrutura ontológica do texto dramático. O que se nota, porém, nesta retórica que vê teatro em textos é que o conhecimento que tem de teatro é tomado como uma evidência (lógica) que ultrapassa práticas, temporalidades variadas, espaços geográficos e culturas, e que sobretudo esquece a sua relação circunstancial com o sujeito que lê.

Compreendo a necessidade de distinguir um texto como Morte de Um Caixeiro Viajante de Descrição de Um Quadro, mas rejeito que essa distinção se faça com base na sua relação com determinada encenação, pois ela apenas funciona para uma ideia de teatro. Aceito uma leitura particular ou contextualizada, uma leitura que tenha em atenção interesses teatrais do autor, mas insisto na possibilidade de que se possa ler uma peça de teatro ignorando esse contexto teatral, muitas vezes simplificador ou redutor e demasiadas vezes preponderante. Descrição de Um Quadro vê-se frequentemente encostado a uma discussão sobre os limites da literatura dramática ou sobre uma tradição antiteatral, e os seus críticos (cf. Haß, 2005) estão sobretudo interessados em descobrir-lhe o teatro de modo a justificar o enquadramento que o autor para ele sinaliza $^{6}$, esquecendo ou ignorando um enorme campo de possibilidades de significados.

Alain Badiou, correspondendo a uma visão comum do texto dramático, descreve-o como lugar da «eternidade do teatro»: «É assim que se explica que, a longo prazo, aquilo que fica do teatro são os textos. Os espetáculos [...] são efémeros, na medida em que as suas negociações são recolocadas em jogo a cada sessão» (Badiou, 2013:59). Mas, se o teatro é

6 Esta afirmação na nota final de Müller em Descrição de Um Quadro é motivo de prolífica exegese: «A acção pode ser uma qualquer, já que as sequências são passado, explosão de memória numa estrutura dramática morta» (Müller, 2015: 61). 
efémero e a literatura a eternidade, como pode a literatura conter uma efemeridade (o teatro) em permanente mutação e sujeita às estéticas, tecnologias, interesses de cada tempo? E como pode um texto, que é literatura, ter nele teatro, quando a encenação se tornou arte autónoma e a pluralidade semântica é hoje tida como riqueza literária de um texto? E porque preciso eu de ver para ler melhor, quando o que vejo é uma proposta interpretativa, logo mediada e digerida, de um texto que tenho a oportunidade de ler eu próprio?

A um dramaturgo que esteja a escrever uma peça, pergunta-se para o que escreve, pressupondo-se que há um espetáculo em vista, uma encomenda de um teatro, um grupo de atores para quem são pensadas as falas. Esta pressuposição teleológica assente numa certa ideia de teatro elimina ou oblitera outra vida para a literatura dramática. A finalidade marca existências, define possibilidades e visibilidade. A literatura dramática é validada pelo teatro. E, se bem que a mesma pergunta possa ser feita à romancista, a resposta que se espera é bem mais imprevisível: para mim, para os amigos, para o mundo, para ganhar dinheiro, para viver, etc. Quem escreve romances não escreve para ninguém, não precisa de um espetáculo para existir. Mas, perante o objeto texto dramático, o leitor tem de encontrar o teatro, a literatura dramática tem de saber o que é teatro, o autor tem de escrever para um espetáculo.

Uma das consequências institucionais deste olhar sobre a relação entre teatro e literatura é considerar-se que é obrigação do teatro defender a literatura dramática para evitar a sua extinção. O Teatro Nacional ou o financiamento às artes performativas devem contemplar quotas para a dramaturgia (nacional ou internacional, contemporânea ou clássica), o teatro deve preservar um repertório dramatúrgico. Se não o fizer, a dramaturgia morre, porque sem teatro não há literatura dramática. Do mesmo modo, os prémios para a literatura dramática requerem ou uma encenação prévia ou uma encenação póstuma, como se este ato viesse atribuir vida e identidade à obra literária (e, a propósito, os prémios literários raramente contemplam o género dramático). Estas circunstâncias, num tempo em que o teatro procura outros pontos de partida, constrangem o encontro dos espetáculos com mundos e disciplinas. Além do mais, fica esquecida uma ligação, também ela histórica, da literatura dramática à literatura. Já que se exige, porque não pedir às edições, editoras, bibliotecas, prémios literários ou aulas de literatura uma defesa deste género literário que impeça a sua extinção? 
Se não há como evitar a construção teleológica e correlacionista (escrever para alguma coisa ou alguém, a literatura dramática em relação com...), então procurem-se outras finalidades, outras relações porque essa abertura possibilita por sua vez outros significados e a libertação da literatura dramática de uma exigência que lhe retira leitores (porquê sempre um espectador ou um encenador?) e leituras (porquê sempre o palco e a «ação»?). Acontece existir, em alguns textos dramáticos, uma relação forte com determinada prática teatral, mas também se encontram textos em reação contra determinado teatro ou com relações fortes com a literatura dramática, com o cinema ou com a censura do seu tempo ou com os direitos das minorias ou com acontecimentos políticos, conflitos, guerras, problemas pessoais, doenças, viuvez, unicórnios, etc.

O DESAPARECIMENTO

O problema da relação entre o teatro e a literatura, tal qual o expus, poderia descrever-se do seguinte modo: eu sei o que é o teatro (ou a literatura) e portanto tentarei aproximar ou afastar a literatura (o teatro) do teatro (da literatura). Este conhecimento assenta numa relação privilegiada que ambas as artes têm entre si: o teatro é a sua relação com a literatura, do mesmo modo que a literatura é a sua relação com o teatro. É por isso que se tenta aproximar ou afastar uma arte da outra. Tal modo de descrever os objetos em causa implica fixá-los a uma identidade que limita tudo o resto que podem ser. Além disso, se teatro é a sua relação com literatura e literatura a sua relação com teatro, as suas identidades estão presas a um círculo aporético que nada revela sobre cada uma das identidades.

Explica-se a sobrevivência destas descrições identitárias por servirem um saber entretanto naturalizado que perpetua tradições de análise e crítica, estrutura uma comunidade e uma retórica, e alimenta uma máquina institucional necessária ao funcionamento de programas de apoio financeiro. No entanto, como tentei demonstrar no caso da afirmação de Osório Mateus, bem como no caso mais abrangente dos textos dramáticos, este saber pode funcionar contra a própria crítica e intenções das instituições, quando se mostra incapaz de reconhecer as suas limitações e vontade de conservar. A sua inflexibilidade abafa significados, exclui identidades e limita o entendimento de asserções consideradas minoritárias. 
Não pretendo aqui defender a necessidade de expulsar o teatro da literatura dramática ou a literatura do teatro, ou de expulsar o ator do teatro ou as luzes ou os linóleos ou as flanelas ou a caixa preta. Apenas tenho vontade de poder fazer um espetáculo sem atores, texto ou flanelas ou caixa preta e que este espetáculo não seja entendido como uma afirmação contra o teatro. Como se se tratasse de um espetáculo «diferente», «reativo», «antiteatral», «adolescente», etc. Este lugar, onde é posto o sujeito que não faz o esperado, neutraliza a sua identidade e desse ponto de vista exerce uma violência que reduz as suas possibilidades de vivência. Como lidar então com uma ideia de teatro e uma lógica correlacional aparentemente hegemónica, consolidada e naturalizada? Será possível pensar em literatura dramática ou teatro esquecendo o seu par antinómico e normativo?

A identificação de um modelo que alimenta os binómios teatro e literatura, literário e antiliterário, igualdade e diferença, maioria e minoria, permite encostar a problemática da relação entre teatro e literatura a uma discussão sobre a identidade assim como sobre o modo como olhamos, descrevemos e conhecemos o outro. O dualismo antinómico que opõe teatro a literatura e que provoca uma cegueira que faz com que, por exemplo, uma crítica estética de filiação teatral ou performática seja incapaz de ler certos autores corresponde a uma vontade de ler uma definição de teatro ou de literatura dramática numa coisa. Por isso se convocam, como utensílios óticos, as grandes antinomias teatrais que sustentam as definições - a tensão entre o real e o ficcional ou a tensão entre o palco e o espectador ou a relação entre teatro e literatura. É como quando uma determinada ideia de negro (e de branco) se antecipa a uma pessoa de pele negra.

A tradição da filosofia epistemológica (desencadeada pelo Iluminismo e o seu legado cartesiano e kantiano) ajuda-nos a ler este preconceito crítico. As diferentes discussões e problemas que se identificam na relação entre teatro e literatura evidenciam a confiança numa ideia de teatro ou de literatura finita e definível, e portanto a vontade de se saber ou conhecer essa definição. Mas as definições de teatro ou literatura dramática são sempre insatisfatórias e sujeitas a confrontar-se com a incoerência. A inoperância crítica deste círculo hermenêutico e os equívocos que o sustentam não significam que se devam apagar ou ostracizar as ideias de teatro, mas apenas tornar percetíveis as suas origens e relativizar a sua importância.

Para resolver, pois, o problema da preponderância da relação antinómica entre teatro e literatura, há que olhar para a disciplina e para o 
espetáculo com uma outra vontade. Já não apenas com a vontade de fixar uma identidade, mas também de lidar com a sua mutabilidade e imprevisibilidade. Reconhecer um texto dramático ou um espetáculo é como Timothy Morton, em Dark Ecology, descreve o reconhecimento de uma espécie

Não há espécies - e no entanto há espécies! E as espécies não têm origem - e no entanto têm! Um ser humano é composto por componentes não-humanas e relaciona-se diretamente com os não-humanos. Os pulmões resultam de uma evolução das bexigas natatórias. E no entanto um ser humano não é um peixe. [...] [H]á mais bactéria em «mim» do que componentes «humanos». Uma forma de vida é o que Derrida chama arrivant ou o que eu chamo strange stranger: é ela própria e no entanto e simultaneamente não ela própria. A ciência contemporânea permite-nos pensar as espécies não como absolutamente inexistentes, mas como flutuantes, entidades espectrais que não estão diretamente e constantemente presentes. Espectral e espécie são, em certo sentido, cognatos. (Morton, 2016: 18)

O campo relacional em que se podem inserir textos e espetáculos é imprevisível, a ponto de a ideia de relação perder a sua força semântica e a sua preponderância identitária. Se todas as identidades são potencialmente relações com todas as identidades, não existe existência fora das relações. E no entanto as coisas existem.

A complexidade de uma coisa resulta de uma estrutura mutável que define existências e está sujeita a uma infinitude de circunstâncias. Estar aberto a este encontro com o que não vemos à partida nem veremos no final significa reconhecer teatro e literatura como sujeitos e não apenas como meros objetos. ${ }^{7}$ Esta inversão ou paralaxe acompanha o movimento anticorrelacionista a que me referi no início do artigo. Inspirado por Heidegger, propõe um reavivar da ontologia face a uma tradição filosófica que, desde Descartes, se concentrou na problemática epistemológica: como posso conhecer o que está fora de mim. Ora, partindo do princípio heideggeriano de que o sujeito que conhece está imerso no mundo, é parte dele, a distinção teórica entre sujeito e objeto perde o seu peso e a reflexão pode concentrar-se em tentar perceber quem é este

7 «Então e aquelas minorias que recusam, a tribo das toupeiras que não vão regressar do além (o que está para lá do "para lá do ensino"), como se não fossem sujeitos, como se quisessem pensar como objetos, como minoria?» (Harney e Moten, 2013: 22). 
sujeito no mundo (Dasein), o que é ser? A vantagem desta deslocação é a de reagir ao que se virá a denominar, sobretudo com o desconstrucionismo posterior (Derrida), a «metafísica da presença», essa necessidade e vontade epistemológica de dar visibilidade às coisas, de as tornar presentes, de as definir e essencializar, objetificando-as e limitando o seu sistema de relações.

Para evitar a redução do mundo, para evitar pois este sistema correlacionista em que se veem encarcerados espetáculos e textos dramáticos, importa reconhecer que teatro e literatura são sobretudo uma ausência, o desaparecimento, um ser no tempo, como diria Heidegger, nunca presente, sempre na sombra e esquivo. As condições excedem-nos e rejeitar esta circunstância é não querer lidar com as próprias limitações, vontades e preconceitos. Como escreve Timothy Morton: «ser uma pessoa significa nunca se ter a certeza de que se é uma pessoa» (2010: 8).

Isto implica uma maior consciência da fragilidade do olhar crítico, da sua sujeição a vontades, tempos, contextos e tradições, o que contribui para debilitar discursos essencialistas e respostas consensuais e intemporais. O privilégio de certas relações na definição de uma identidade não tem de estar sujeito a uma lógica antinómica, correlacional ou de interdependência. As relações podem ser efémeras, precárias, enviesadas, ilógicas, inexplicáveis e tantas outras coisas que a sua precedência na identidade de um objeto perde significado. Só assim se está disponível para o imprevisto, a não-relação, para o facto de um espectador que dorme também ser um espectador, um leitor que lê às metades ou que do texto apenas recorda onde foi lido também ser um leitor ou um texto dramático também ser um objeto, um animal, um espetáculo ou um espelho sem nunca deixar de ser um texto dramático. 


\section{REFERÊNCIAS BIBLIOGRÁFICAS}

BADIOU, Alain (2013), Éloge du Théâtre, Paris, Flammarion.

BARISH, Jonas (1985), The Antitheatrical Prejudice, Berkeley / Los Angeles / Londres, University of California Press. BIET, Christian / TRIAU, Christophe (2006), Qu'est-ce que le théâtre?, Paris, Gallimard.

Corssen, Stefan (1998), Max Herrmann und die Anfänge der Theaterwissenschaft. Mit teilweise unveröffentlichten Materialien, Tubinga, Max Niemeyer Verlag.

HARMAN, Graham (2002), Tool-Being: Heidegger and the Metaphysics of Objects, Chicago e La Salle, Illinois, Open Court Publishing.

- (2007), Heidegger Explained: From Phenomenon to Thing, Chicago e La Salle, Illinois, Open Court Publishing.

HAR N y, Stefano / MOTEN, Fred (2013), The Undercommons: Fugitive Planning \& Black Study, Nova Iorque, Minor Compositions.

HAss, Ulrike (ed.) (2005), Heiner Müller-Bildbeschreibung. Ende der Vorstellung, Berlim, Verlag Theater der Zeit.

HEIDE G G ER, Martin (2008), A Origem da Obra de Arte, Lisboa, Edições 70.

KLIER, Helmar (ed.) (1981), Theaterwissenschaften im deutsprachigen Raum. Texte zum Selbstverständnis, Darmstadt, Wissenschaftliche Buchgesellschaft.

LeHmann, Hans-Thies (2005), Postdramatisches Theater, Frankfurt am Main, Verlag der Autoren (ed. port. Teatro Pós-Dramático, Orfeu Negro, 2017).

MATEus, Osório (2002), De Teatro e Outras Escritas, Lisboa, Quimera Editores.

MeIllassoux, Quentin (2006), Après la finitude: Essai sur la nécessité de la contingence, Paris, Seuil.

MORTON, Timothy (2010), The Ecological Thought, Cambridge / Massachusetts / Londres, Harvard University Press.

- (2016), Dark Ecology: For a Logic of Future Coexistence, Nova Iorque, Columbia University Press.

MÜLLER, Heiner (2015), Quarteto e Outras Peças, Lisboa, Artistas Unidos/Livros Cotovia.

SARrazAC, Jean-Pierre (2012), Poétique du drame moderne: De Henrik Ibsen à Bernard-Marie Koltès, Paris, Seuil. szondi, Peter (1996), Theorie des modernen Dramas (1880-1950), Frankfurt am Main, Suhrkamp Verlag.

vieira MENDEs, José Maria (2016), Uma Coisa não É Outra Coisa, Lisboa, Livros Cotovia.

\section{JOSÉ MARIA VIEIRA MENDES}

José Maria Vieira Mendes escreve maioritariamente peças de teatro. É membro do Teatro Praga desde 2008. As suas peças foram traduzidas em mais de uma dezena de línguas. Publicou mais recentemente um ensaio (Uma Coisa não É Outra Coisa) e uma compilação de peças (Uma Coisa), ambos pelos Livros Cotovia. 